\title{
Effects of the Vibration Amplitude in Vibratory Stress Relief on the Fatigue Life of Structures
}

\author{
Cuong Bui Manh ${ }^{1, *}$, Duong Nguyen $\operatorname{Van}^{2}$, Si Do Van ${ }^{1}$, Manh Phan Van ${ }^{1}$, Van Thao Le ${ }^{3}$ \\ ${ }^{1}$ Department of Engineering Mechanics, Le Quy Don Technical University, Hanoi, Vietnam \\ ${ }^{2}$ Department of Materials Science and Engineering, Le Quy Don Technical University, Hanoi, Vietnam \\ ${ }^{3}$ Advanced Technology Center, Le Quy Don Technical University, Hanoi, Vietnam \\ Received 16 October 2021; received in revised form 08 December 2021; accepted 09 December 2021
}

DOI: https://doi.org/10.46604/aiti.2021.8714

\begin{abstract}
This research aims to investigate the effects of vibration amplitude in vibratory stress relief (VSR) on the fatigue strength of structures with residual stress. Experiments are carried out on specimens with residual stress generated by local heating. Flat specimens made of A36 steel are prepared to be suitable for setting up fatigue bending tests on a vibrating table. Several groups of samples are subjected to VSR at resonant frequencies with different acceleration amplitudes. The results show that VSR has an important influence on the residual stress and fatigue limit of steel specimens. The maximum residual stress in the samples is reduced about $73 \%$ when the amplitude of vibration acceleration is $57 \mathrm{~m} / \mathrm{s}^{2}$. The VSR method can also improve the fatigue limit by up to $14 \%$ for steel samples with residual stress.
\end{abstract}

Keywords: vibratory stress relief (VSR), residual stress, fatigue life, fatigue limit, vibration amplitude

\section{Introduction}

Residual stress is the internal stress existing between parts of workpieces in the absence of external loads. This stress is generated when the workpieces experience inhomogeneous deformation, e.g., heating, cooling, and plastic deformation [1-2]. Many technological processes, such as welding, quenching, and metal forming, can produce residual stress. Residual stress often leads to the loss in the geometry accuracy of workpieces after machining, and causes the degradation of corrosion resistance in various environments [3]. Residual stress also has effects on the mechanical properties of materials and therefore on the load-bearing capacity and life service of components. Especially, the tensile residual stress which usually appears in welding has negative effects on the fatigue limit and fatigue life of workpieces [4-5].

Relieving residual stress is one of the major concerns in mechanical engineering processes. There are many relieving methods implemented in manufacturing: annealing, local heating, monotonic overloading, shot pinning, vibratory stress relief (VSR), etc. Among the mechanical methods for relieving residual stress, VSR is considered an effective, flexible, inexpensive, and eco-friendly solution [6-8]. In VSR, cyclic external loads are applied to the workpieces with residual stress for a certain length of time, and this process is believed to cause microplastic deformation in micro regions of the workpieces and lead to the relaxation of residual stress [8-9]. This technology has been successfully implemented in the manufacturing of many important workpieces, such as welded shafts, marine shafts, large rails, large surface plates from stainless steel, and thin parts from aluminum alloy [10-13].

There have been lots of publications investigating the VSR effects on the residual stress state and the mechanical properties of specimens [7-8, 12, 14-16]. However, the research examining the VSR effects on the fatigue characteristics of workpieces is still limited. Fang et al. [17] demonstrated that the fatigue life of welding steel samples could be improved up to

* Corresponding author. E-mail address: buimanhcuongkck@lqdtu.edu.vn 
$25 \%$ by using VSR. Munsi et al. [18] also carried out a study on VSR for welded steel bars at non-resonant frequency with two load levels for a short interval of time, only $5 \mathrm{~s}$. They found that applying VSR at high loads and a small number of cycles could reduce the residual stress and increase the fatigue life of structures up to $17 \%$. Meanwhile, the thermal method could reduce the residual stress and reduce the fatigue life of structures up to 43\%. Djuric et al. [19] studied the VSR effects on the properties of martensitic steel, and found an increase of fatigue damage due to the applied VSR treatment. In the work of Gao et al. [20], the fatigue characteristics of Ti-6Al-4V titanium alloys were determined after VSR at different vibration amplitudes. The fatigue limit of samples was found to be slightly reduced with the increasing VSR amplitude (several percent to 10\%) while the residual stress could also be reduced up to 60\%. Song and Zhang [21] applied VSR for 7075-T651 aluminum alloy, and found that the fatigue life of specimens could be enhanced to $6.3 \%$ with the help of VSR. Gao et al. [22] also conducted VSR for 7075-T651 aluminum alloy, and concluded that low amplitude VSR could reduce the residual stress and improve the fatigue life of 7075-T651 aluminum alloy.

In this study, VSR is conducted on specimens of ASTM A36 steel, which is a popular material for weld structures. The residual stress is created by local heating, which is similar to the welding process and different from the pre-strain method in recent literature [19, 21-22]. Fatigue bending tests are conducted on a vibrating table with flat specimens, and the fatigue limit is determined by an improved staircase method. Herein, this study focuses on the effects of VSR amplitude on the fatigue properties of A36 steel with residual stress, demonstrating the VSR ability of reducing the residual stress and improving the fatigue limit.

\section{Materials and Experimental Methods}

\subsection{Test specimens}

In this work, fifty-five identical flat test specimens, which are designed according to ASTM E466 for bending fatigue tests, are extracted from a large carbon steel panel (Fig. 1). The specimens' thickness is $6 \mathrm{~mm}$. The end part of each specimen is with a threaded hole M5 (Fig. 1(a)) to attach additional weight, which creates an addition flat bending load and increases the stress at the A-A cross-section during the vibration test. Tables 1 and 2 present the mechanical properties (e.g., density, modulus, and yield strength (YS)) and the chemical compositions of the carbon steel specimens.

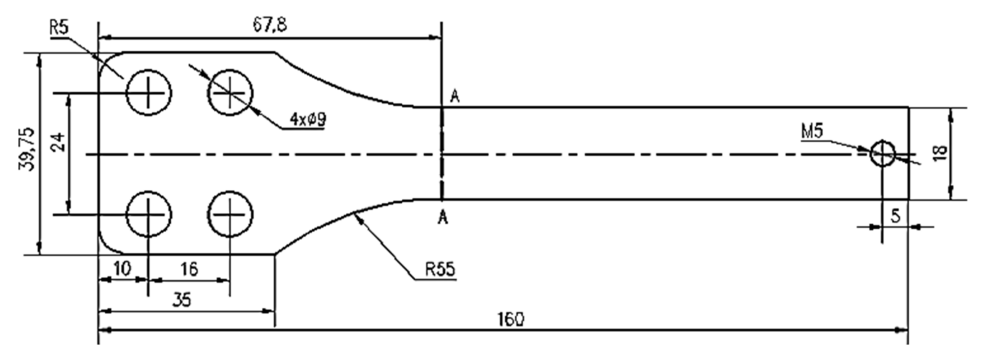

(a) Geometry and dimensions of specimens

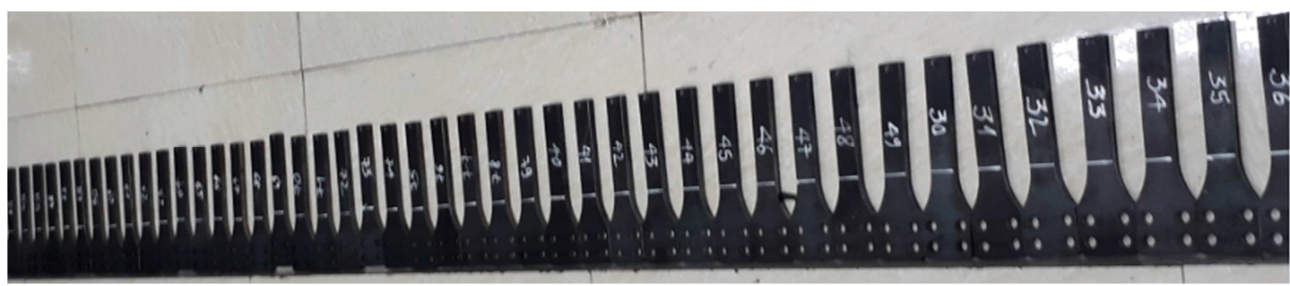

(b) Fabricated specimens

Fig. 1 Design and preparation of specimens

Table 1 Mechanical properties of low carbon steel

\begin{tabular}{|c|c|c|c|c|}
\hline $\begin{array}{c}\text { Density } \\
\left(\mathrm{kg} / \mathrm{m}^{3}\right)\end{array}$ & $\begin{array}{c}\text { Modulus of } \\
\text { elasticity }(\mathrm{GPa})\end{array}$ & Poisson's ratio & $\begin{array}{c}\text { Yield strength } \\
(\mathrm{MPa})\end{array}$ & $\begin{array}{c}\text { Ultimate tensile } \\
\text { strength }(\mathrm{MPa})\end{array}$ \\
\hline 7850 & 200 & 0.3 & 296 & 440 \\
\hline
\end{tabular}


Table 2 Chemical compositions of specimens

\begin{tabular}{|c|c|c|c|c|c|c|c|c|c|}
\hline Element & $\mathrm{C}$ & $\mathrm{Si}$ & $\mathrm{Mn}$ & $\mathrm{P}$ & $\mathrm{S}$ & $\mathrm{Cr}$ & $\mathrm{Mo}$ & $\mathrm{Ni}$ & $\mathrm{Al}$ \\
\hline wt. \% & 0.1452 & 0.0087 & 0.4483 & 0.0139 & 0.0028 & 0.0054 & 0.0030 & 0.0091 & 0.0723 \\
\hline Element & $\mathrm{Co}$ & $\mathrm{Cu}$ & $\mathrm{Ti}$ & $\mathrm{V}$ & $\mathrm{Nb}$ & $\mathrm{W}$ & $\mathrm{Pb}$ & $\mathrm{Fe}$ & \\
\cline { 1 - 7 } wt. \% & 0.0080 & 0.0118 & $<0.0010$ & $<0.0020$ & 0.0041 & 0.0470 & $<0.0100$ & 99.183 &
\end{tabular}

\subsection{Generation of the residual and dynamic stress in specimens}

First, for each steel specimen, high residual stress is induced by spot heating in the transition zone (Fig. 2(a)). The displacement velocity of the heat source and the heating time are controlled so that the temperature at the center of the heating zone is around $1000^{\circ} \mathrm{C}$. The heat source is moved along line A-A (Fig. 1(a)) at a speed of $2 \mathrm{~mm} / \mathrm{s}$. After the local heating, each sample is rapidly cooled to room temperature by quickly putting it into a water tank. To monitor the dynamic strain and stress, an HBM strain gage (type 1-LM11-3/350GE) is bonded onto the middle of line A-A. The strain gauge is attached to the surface of specimens in the region of interest (RoI) (Fig. 2(b)).

The dynamic stress is generated and controlled by varying the exciting acceleration amplitude and maintaining the constant frequency of a shaker. Therefore, it is necessary to survey the relationship between the exciting acceleration amplitude of the samples and the dynamic stress generated at the cross-section (A-A) before conducting VSR and fatigue tests.

An LDS electrodynamic shaker (model V830-335T) with an LDS LASER USB Vibration Controller (model LAS200, S/N 10870124) is used for generating the vibration of the samples. An LMS noise and vibration test system (LMS SCADAS mobile system) is used for signal acquisition, monitoring the displacement at the end of the samples and the dynamic strain in RoI, as shown in Fig. 3(a).

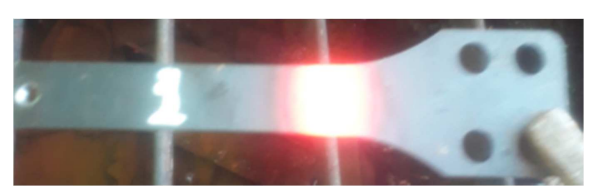

(a) Location of local heating to create residual stress

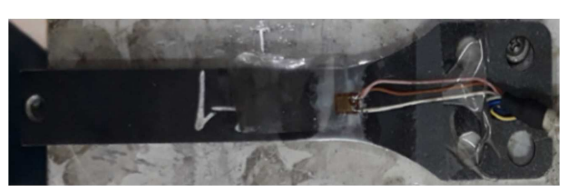

(b) Strain gauge attachment on a specimen

Fig. 2 Generating residual stress and attaching a strain gage to monitor the dynamic strain and stress

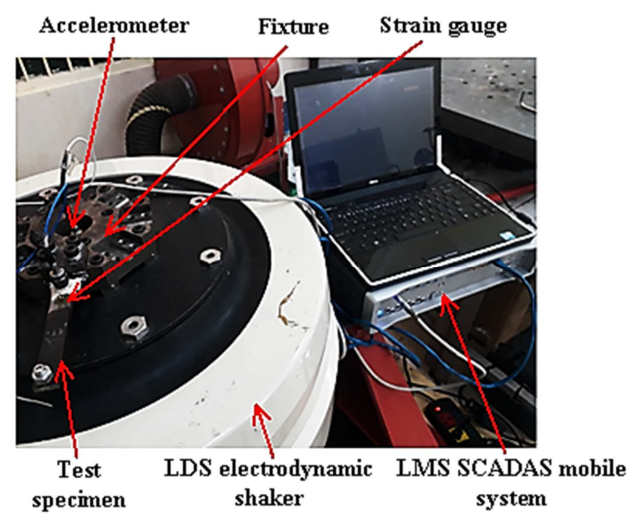

(a) The LMS noise and vibration test system and the experimental setup

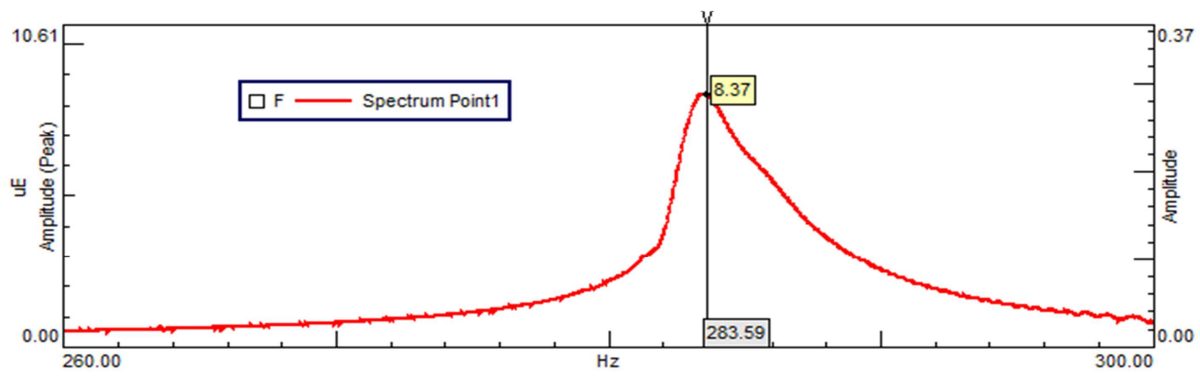

(b) Natural frequency of a sample with residual stress

Fig. 3 Experiment for monitoring the displacement and the dynamic strain in RoI 
The data acquired by the LMS SCADAS mobile system enables studying and establishing the relationship of the exciting frequency and acceleration amplitude with the dynamic strain and stress. The sine vibration experiment is set at $30 \mathrm{~m} / \mathrm{s}^{2}$ with a frequency range from 260 to $300 \mathrm{~Hz}$. A sweep rate is set at $0.25 \mathrm{oct} / \mathrm{min}$ to exactly determine the resonance frequency of test specimens. The specimens are heated locally to generate the residual stress. The transmissibility function is used for the resonance search, and is computed based on the ratio of the dynamic strain and exciting acceleration, as shown in Fig. 3(b). Fig. 3(b) shows that the resonant frequency of the test specimens with residual stress is about $283.59 \mathrm{~Hz}$. After the controller finds the resonant frequencies in the sweep range, the sine dwell tests are performed. The controller runs a single sine tone at the resonant frequency instead of sweeping through the frequency range, with the acceleration amplitudes of $60 \mathrm{~m} / \mathrm{s}^{2}, 90 \mathrm{~m} / \mathrm{s}^{2}, 120$ $\mathrm{m} / \mathrm{s}^{2}, 150 \mathrm{~m} / \mathrm{s}^{2}$, and $180 \mathrm{~m} / \mathrm{s}^{2}$, respectively. Subsequently, the dynamic stress is calculated from the dynamic strain by Hook's law, as shown in Eq. (1).

$$
\sigma=E \times \mathcal{E}
$$

where $\sigma$ is the stress $\left(\mathrm{N} / \mathrm{m}^{2}\right), \varepsilon$ is the strain $(\mathrm{m} / \mathrm{m})$, and $E$ is the modulus of elasticity $\left(\mathrm{N} / \mathrm{m}^{2}\right)$.

\subsection{VSR tests}

VSR tests are conducted on the LDS electrodynamic shaker in a scheme like the one in dynamic stress tests. 56 specimens are randomly selected and divided into 7 groups denoted by A, B, C, D, E, F, and G. Each group consists of 8 test specimens. Three test specimens in group A are randomly selected to measure the residual stress before VSR, and the remaining five samples of group A are used for determining the fatigue limit. The VSR processes are conducted for the specimens in 6 groups (B, C, D, E, F, and G) using the LDS electrodynamic shaker with the acceleration amplitudes of 29 $\mathrm{m} / \mathrm{s}^{2}, 43 \mathrm{~m} / \mathrm{s}^{2}, 57 \mathrm{~m} / \mathrm{s}^{2}, 71 \mathrm{~m} / \mathrm{s}^{2}, 99 \mathrm{~m} / \mathrm{s}^{2}$, and $156 \mathrm{~m} / \mathrm{s}^{2}$, respectively. Each sample in these 6 groups is stimulated by the shaker within 10 minutes. The exciting frequency is set at $283.59 \mathrm{~Hz}$ according to the resonant frequency of the test specimens. After the VSR processes, three samples in each group (B, C, D, E, F, and G) are randomly selected to measure and check the residual stress, and the remaining five test specimens are used for determining the fatigue limit. The diagram of using different test specimen groups is shown in Fig. 4.

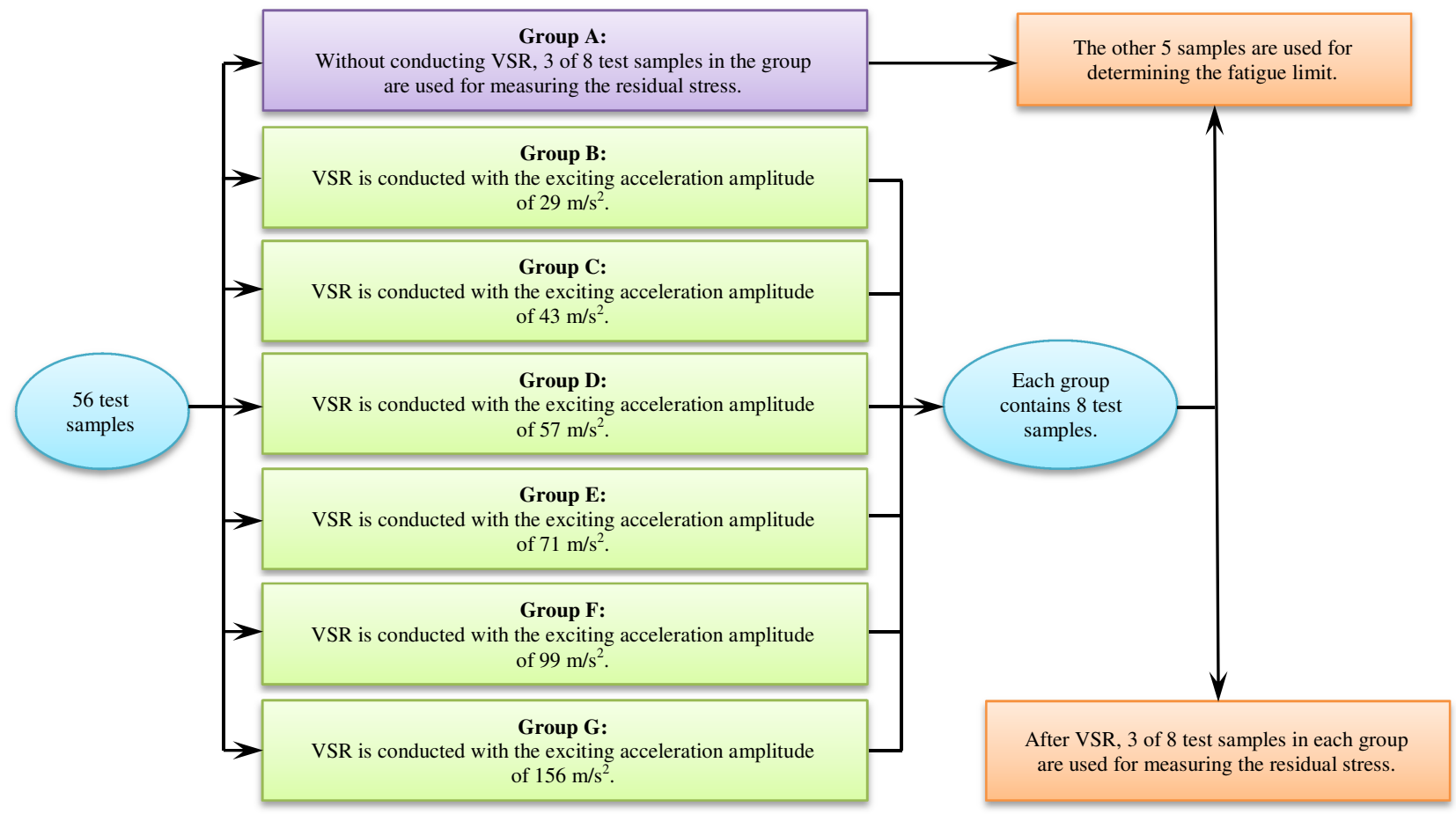

Fig. 4 Diagram of different specimen groups 


\subsection{Measuring residual stress}

Three test specimens of group A are used for measuring the residual stress; the measured value is considered the residual stress before VSR. For the other 6 groups (B, C, D, E, F, and G), after VSR is conducted, three samples are randomly chosen from each group for the measurement of residual stress. The residual stress on the samples before and after VSR is then compared to each other to assess the ability of reducing the residual stress in different loading modes.

The measurement of residual stress is performed according to ASTM E837-13a [23], using a RS200 system (Vishay Group, USA) and an EA-06-062RE-120 strain gauge rosette. Fig. 5 shows the residual stress measuring system marked RS200. When measuring the residual stress, the electrical resistance-strain gauge rosettes are attached to the surface of specimens in the same position as in the measurement of dynamic strains (Fig. 3(b)). The residual stress on the surface layer is determined by ASTM E837-13a, as described in the work of Gao et al. [16].

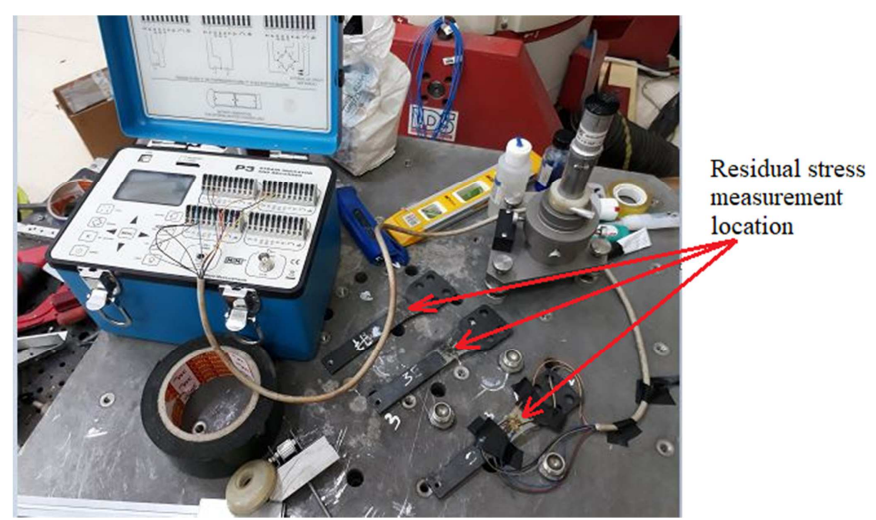

Fig. 5 Specimens and the residual stress measuring system marked RS200

\subsection{Fatigue test}

The fatigue tests with a flat bending load are also conducted on the LDS electrodynamic shaker, as shown in Fig. 6. In each group, 5 test samples are used to determine the fatigue limit. The fatigue test parameters are as follows: the frequency of fatigue vibration test at the resonance frequency of samples is $283.59 \mathrm{~Hz}$, the stress ratio is -1 , the ambient temperature is $27^{\circ} \mathrm{C}$, and the humidity is $60 \%$.

The fatigue limit can be determined by using the staircase method [24-25] (Fig. 7). The test is performed for the first specimen at a stress level around the fatigue limit. If the result of the above test is "non-fracture", the second specimen is tested at the stress level with an increment of $d$. On the other hand, if the result is "fracture", the second specimen is tested at the stress level with a decrement of $d$. The fatigue test is repeated until a given number of specimens is used, then the fatigue limit is calculated. This fatigue test method has been widely accepted to examine the fatigue limit of metals. There were also some modified staircase procedures to reduce the number of test specimens and hence lower the cost and running time of this test [26-27].

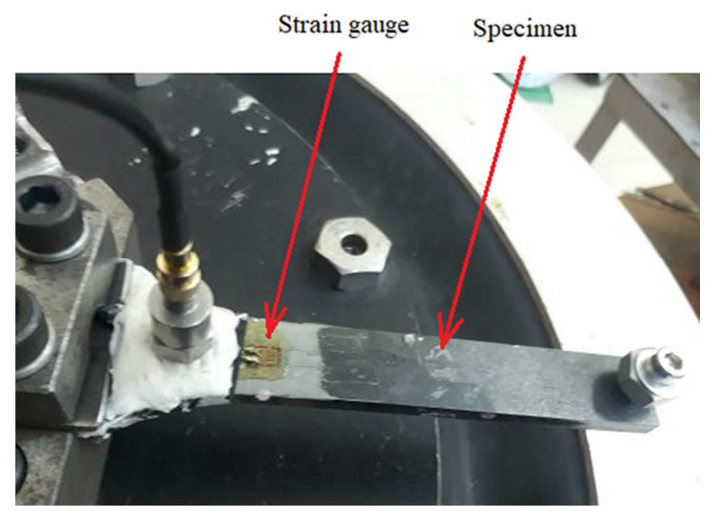

Fig. 6 A Specimen and strain gauge in the fatigue test on the LDS electrodynamic shaker 


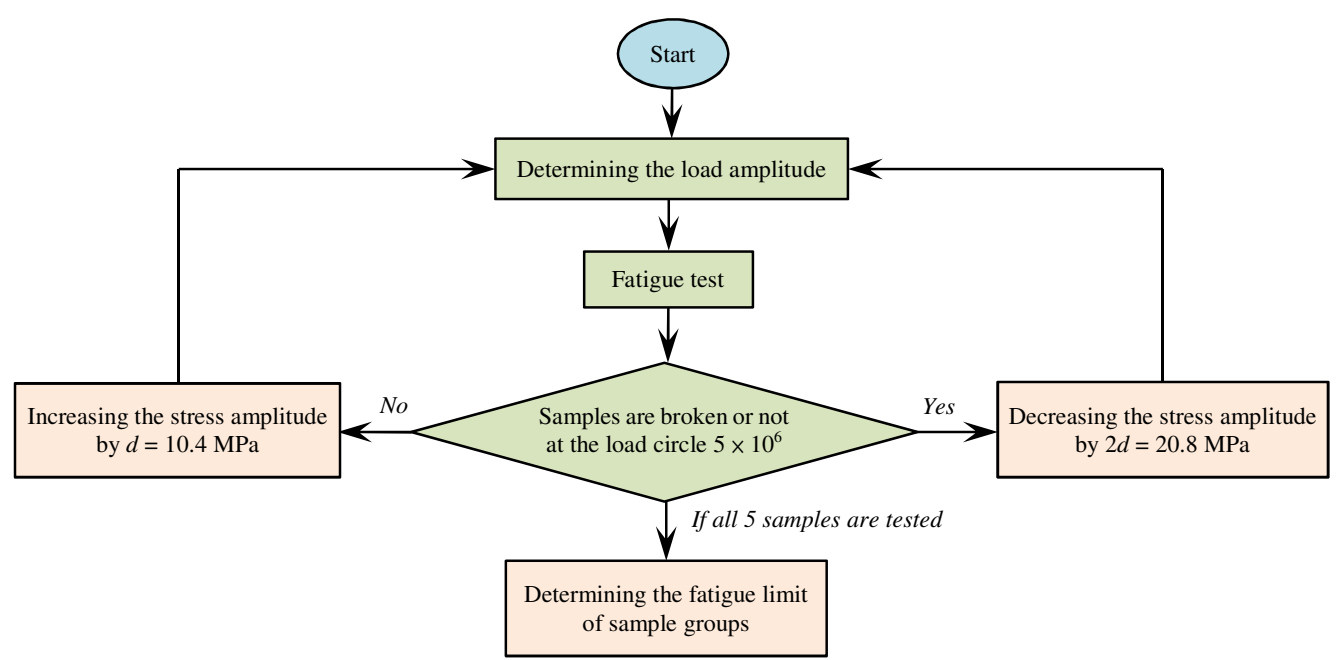

Fig. 7 Diagram illustrating the process of determining the fatigue limit

In this study, a modified staircase method proposed by International Council for Combustion Engines is implemented for bending fatigue tests with a limited number of specimens [28]. Herein, the first specimen is subjected to a stress level that is most likely well below the average fatigue strength. When this specimen survives $5 \times 106$ cycles, this same specimen is subjected to a stress level one increment above the previous. This is continued with the same specimen until failure. Then, the number of cycles is recorded, and the next specimen is subjected to a stress that is at least 2 increments below the level where the previous specimen fails. The first stress amplitude level is determined, depending on the tensile strength of the material and according to the following empirical expression [29]:

$$
\sigma_{1}=0.68 \times\left(0.55-0.0001 \times \sigma_{u}\right) \times \sigma_{u}
$$

where $\sigma_{u}$ is the material tensile strength. When $\sigma_{u}=440 \mathrm{MPa}$, the first stress amplitude level $\sigma_{1}$ is about $152 \mathrm{MPa}$.

The next stress level applied on a specimen is determined by the results obtained in the preceding test. If the preceding specimen, $i$, fails at the level $\sigma_{i}$, the next stress level will be $\sigma_{i+1}=\sigma_{i}-2 d$. If the preceding specimen is not broken, $\sigma_{i+1}=\sigma_{i}+$ $d$, where $d$ is a predefined difference in applied stress levels. In this study, $d$ is determined as $d=0.068 \times \sigma_{l} \approx 10.4 \mathrm{MPa}$. The fatigue testing results of five samples in group $\mathrm{C}$ is illustrated in Fig. 8. There are 5 specimens that undergo the bending tests. The first specimen is broken in the third test at a stress level of $\sigma_{2}$. Therefore, the second specimen is firstly tested at a stress level $\sigma_{0}=\sigma_{3}-$ $2 d$, and then it is tested at elevated stress levels until it is broken at the fourth test with a stress level of $\sigma_{3}$. Subsequently, the third specimen is tested, and the tests are repeated until the fifth specimen is broken.

Based on the test results as shown in Fig. 8, the fatigue limit is calculated by Eq. (2) [24]:

$$
\sigma_{R}=\sigma_{0}+d\left(\frac{A}{F} \pm \frac{1}{2}\right)
$$

where $\sigma_{0}$ is the lowest stress level $(i=0)$ in which the less frequent event run-out appears; $F$ and $A$ are the parameters calculated by Eqs. (4) and (5).

$$
\begin{aligned}
& F=\sum i \\
& A=\sum f_{i}
\end{aligned}
$$

where $i$ is the number of stress levels, and $f_{i}$ is the number of run-outs obtained at the stress level $i$. 


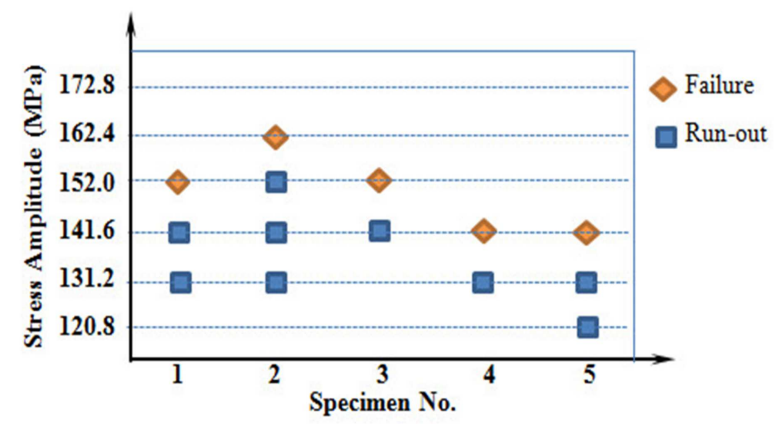

Fig. 8 Log sheet of a modified staircase test

\section{Results and Discussion}

\subsection{Dynamic stress}

The correlation between the exciting acceleration amplitude and the strain amplitude on the surface of test specimens in RoI is shown in Fig. 9. With each case of the exciting acceleration amplitude, there is a corresponding graph that shows the change of strain over time. It can be seen that, in the sweep sine mode, the largest strain response is achieved when the exciting frequency of the LDS shaker coincides with the natural frequency of the samples.

Fig. 10 shows the dynamic stress at different exciting acceleration amplitudes. This dynamic stress-vibration acceleration correlation can be approximately estimated by Eq. (6):

$$
\sigma=2.1049 \times A+47.953
$$

where $A$ is the amplitude of vibration acceleration $\left(\mathrm{m} / \mathrm{s}^{2}\right) ; \sigma$ is the principal stress on the surface of test specimens in RoI (MPa). It is revealed that the dynamic stress linearly increases with the amplitude of vibration acceleration.

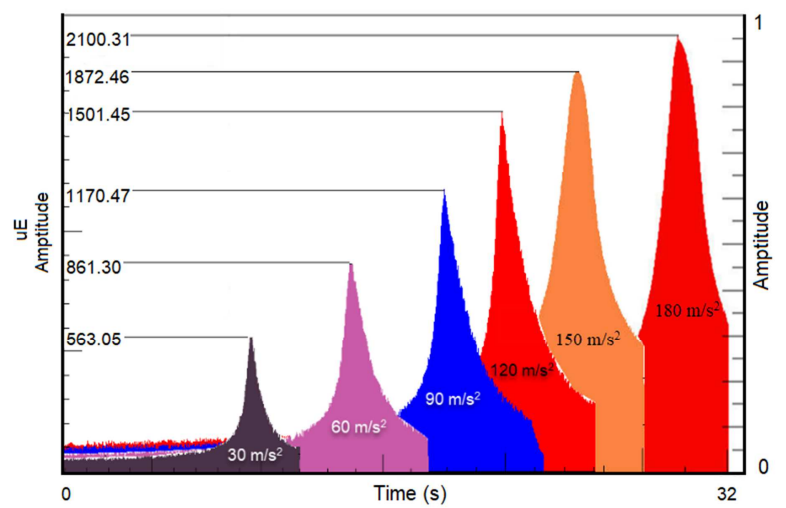

Fig. 9 Correlation between strain and amplitude of vibration acceleration

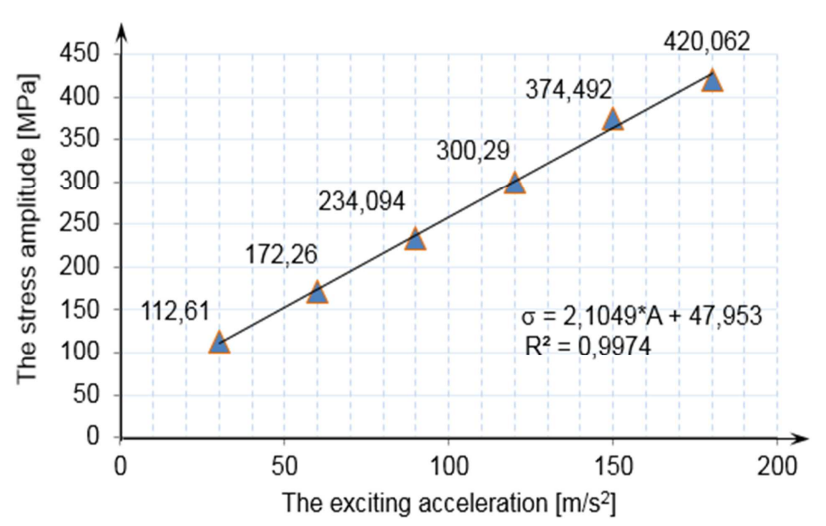

Fig. 10 Dependence of stress on exciting acceleration

\subsection{Residual stress and fatigue limit}

The results of measuring residual stress according to ASTM E837-13a include a variety of stress components. To compare and match with the results of dynamic stress measurement, the residual stress components will be chosen as the first principal stress. The residual stress of the samples after VSR is shown in Fig. 11. It is noted that the samples without VSR are considered the ones with the vibration amplitude of zero.

It is clear that the residual stress will be reduced when the amplitude of exciting acceleration increases. According to the graph, the residual stress in the samples without using VSR is $216 \mathrm{MPa}$. In all the cases using VSR, the residual stress is reduced by more than $36 \%$. In particular, the maximum residual stress reduction can be attained by up to $73 \%$ when the 
vibration amplitude reaches $57 \mathrm{~m} / \mathrm{s}^{2}$. This is corresponding to the total stress exceeding $30 \%$ of the YS of the material. In contrast, when the amplitude of vibration acceleration exceeds $57 \mathrm{~m} / \mathrm{s}^{2}$, the residual stress will increase as the vibration amplitude increases. This may be explained by the intensive deformation of the samples.

The process of determining the fatigue limit of sample groups is conducted according to the modified staircase method and is shown in Fig. 7. The experimental data is processed, and the final results of the fatigue limit are given in Fig. 12. The experimental results of the fatigue limit demonstrate that the fatigue limit of samples is generally increased with the VSR treatment. The fatigue limit of test specimens increases as the vibration acceleration amplitude increases from 0 to $57 \mathrm{~m} / \mathrm{s}^{2}$, and it reaches a peak of $14 \%$ when the vibratory exciting acceleration amplitude is $57 \mathrm{~m} / \mathrm{s}^{2}$. After that, if the vibratory exciting acceleration amplitude continues increasing, the fatigue limit will gradually decrease. The result is in good agreement with the studies on tensile fatigue characteristics after VSR [19, 21]. It is obvious from the tests that, if the amplitude of the vibration acceleration is very high, the fatigue limit of specimens will be decreased to the value even lower than the value of the samples without VSR. In general, if the vibration amplitude in VSR is too high or the VSR time is too long, micro voids will be formed and specimens' fatigue limit will be lowered.

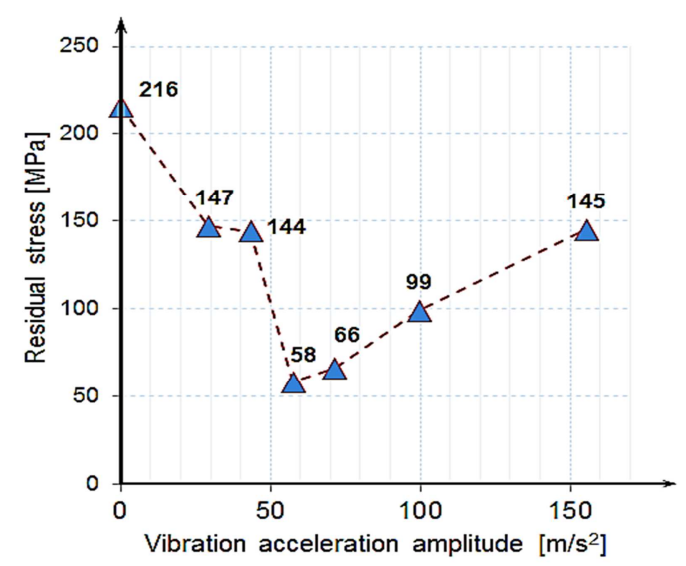

Fig. 11 Residual stress in post-vibrating samples with different vibration acceleration amplitudes

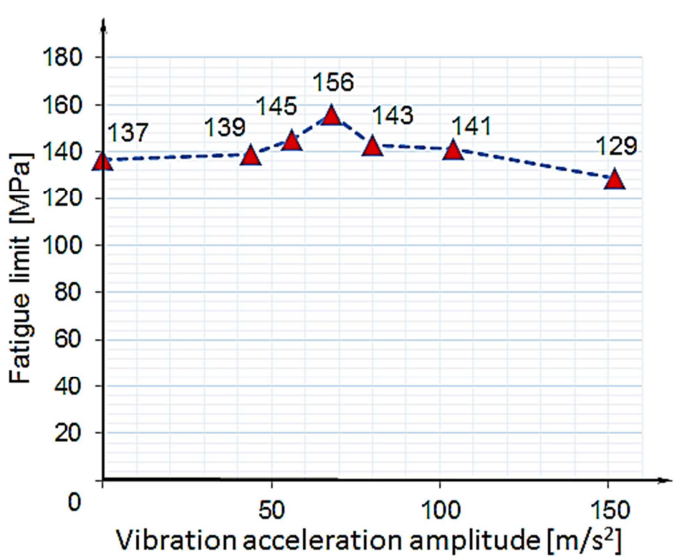

Fig. 12 Fatigue limit of sample groups according to vibration acceleration amplitudes

\section{Conclusions}

In this study, the VSR effects on the residual stress and fatigue limit of samples are investigated. The key findings of this research are described as follows:

(1) The dynamic stress generated through VSR has a linear relationship with the amplitude of vibratory exciting acceleration. At the amplitude of vibratory exciting acceleration lower than $57 \mathrm{~m} / \mathrm{s}^{2}$, the residual stress is reduced with the increase in the amplitude of vibratory exciting acceleration. The maximum principal residual stress is reduced about $73 \%$ when the amplitude of vibratory exciting acceleration is equal to $57 \mathrm{~m} / \mathrm{s}^{2}$. As the amplitude of vibratory exciting acceleration exceeds $57 \mathrm{~m} / \mathrm{s}^{2}$, the residual stress will increase. However, it is generally still lower than those in the cases without using VSR.

(2) VSR also has an effect on the fatigue limit of the samples made from low-carbon steel with residual stress. VSR can improve the fatigue limit by up to $14 \%$ for the samples under residual stress. However, if the vibrating samples are with very high amplitude of acceleration, their fatigue limit will be reduced to the values that are lower than those without VSR.

(3) When the vibrating test samples are with moderate acceleration amplitude, VSR is able to both reduce the residual stress and increase the fatigue limit. If the amplitude of vibration acceleration is very high, this effect will be possibly reversed. The residual stress will be improved less, and the fatigue limit can be lower than the cases without VSR. 


\section{Symbols and Abbreviated Terms}

\begin{tabular}{|c|c|c|}
\hline Symbol & Unit & Definition \\
\hline VSR & - & Vibratory stress relief \\
\hline YS & $\mathrm{MPa}$ & Yield strength \\
\hline$\sigma$ & $\mathrm{MPa}$ & Stress \\
\hline$\varepsilon$ & $\mathrm{m} / \mathrm{m}$ & Strain \\
\hline$E$ & $\mathrm{MPa}$ & Modulus of elasticity \\
\hline$\sigma_{u}$ & $\mathrm{MPa}$ & Material tensile strength \\
\hline$\sigma_{1}$ & $\mathrm{MPa}$ & The first stress amplitude level \\
\hline$\sigma_{i}$ & $\mathrm{MPa}$ & The $i^{\text {th }}$ stress level \\
\hline$\sigma_{0}$ & $\mathrm{MPa}$ & The lowest stress level $(i=0)$ \\
\hline$\sigma_{R}$ & $\mathrm{MPa}$ & Fatigue limit \\
\hline$d$ & $\mathrm{MPa}$ & Predefined difference in applied stress levels \\
\hline$A$ & $\mathrm{~m} / \mathrm{s}^{2}$ & Amplitude of vibration acceleration \\
\hline
\end{tabular}

\section{Conflicts of Interest}

The authors declare no conflict of interest.

\section{References}

[1] J. S. Robinson, M. S. Hossain, and C. E. Truman, "Residual Stresses in the Aluminum Alloy 2014A Subject to PAG Quenching and Vibratory Stress Relief," The Journal of Strain Analysis for Engineering Design, in press.

[2] Q. Wu, D. P. Li, and Y. D. Zhang, "Detecting Milling Deformation in 7075 Aluminum Alloy Aeronautical Monolithic Components Using the Quasi-Symmetric Machining Method,” Metals, vol. 6, no. 4, 80, April 2016.

[3] M. J. Vardanjani, M. Ghayour, and R. M. Homami, "Analysis of the Vibrational Stress Relief for Reducing the Residual Stresses Caused by Machining,” Experimental Techniques, vol. 40, no. 2, pp. 705-713, April 2016.

[4] H. Sasahara, "The Effect on Fatigue Life of Residual Stress and Surface Hardness Resulting from Different Cutting Conditions of $0.45 \%$ C Steel," International Journal of Machine Tools and Manufacture, vol. 45, no. 2, pp. 131-136, February 2005.

[5] M. Benedetti, V. Fontanari, P. Scardi, C. A. Ricardo, and M. Bandini, "Reverse Bending Fatigue of Shot Peened 7075-T651 Aluminum Alloy: The Role of Residual Stress Relaxation,” International Journal of Fatigue, vol. 31, no. 8-9, pp. 1225-1236, 2009.

[6] M. S. Patil, R. R. Wayakole, and K. D. Sarode, "Vibratory Residual Stress Relief in Manufacturing-A Review", International Journal of Engineering Sciences and Research Technology, vol. 6, no. 5, pp. 609-613, May 2017.

[7] H. Song, H. Gao, Q. Wu, and Y. Zhang, "Effects of Segmented Thermal-Vibration Stress Relief Process on Residual Stresses, Mechanical Properties and Microstructures of Large 2219 Al Alloy Rings," Journal of Alloys and Compounds, vol. 886, 161269, December 2021.

[8] C. A. Walker, A. J. Waddell, and D. J. Johnston, "Vibratory Stress Relief-An Investigation of Underlying Process,” Proc. of the Institution of Mechanical Engineers, Part E: Journal of Process Mechanical Engineering, vol. 209, no. 1, pp. 51-58, February 1995.

[9] G. Cai, Y. Huang, and Y. Huang, "Operating Principal of Vibratory Stress Relief Device Using Coupled Lateral-Torsional Resonance," International Journal of Vibroengineering, vol. 19, no. 6, pp. 4083-4097, 2017.

[10] M. C. Sun, Y. H. Sun, and R. K. Wang, "The Vibratory Stress Relief of a Marine Shafting of 35\# Bar Steel," Materials Letters, vol. 58, no. 3-4, pp. 299-303, January 2004.

[11] D. Rao, J. Ge, and L. Chen, "Vibratory Stress Relief in Manufacturing the Rails of a Maglev System," Journal of Manufacturing Science and Engineering, vol. 126, no. 2, pp. 388-391, May 2004.

[12] D. Rao, D. Wang, L. Chen, and C. Ni, "The Effectiveness Evaluation of 314L Stainless Steel Vibratory Stress Relief by Dynamic Stress," International Journal of Fatigue, vol. 29, no. 1, pp. 192-196, January 2007.

[13] H. Gong, Y. Sun, Y. Liu, Y. Wu, Y. He, X. Sun, et al., "Effect of Vibration Stress Relief on the Shape Stability of Aluminum Alloy 7075 Thin-Walled Parts,” Metals, vol. 9, no. 1, 27, January 2019. 
[14] C. Walker, "A Theoretical Review of the Operation of Vibratory Stress Relief with Particular Reference to the Stabilization of Large-Scale Fabrications," Proc. of the Institution of Mechanical Engineers, Part L: Journal of Materials: Design and Applications, vol. 225, no. 3, pp. 195-204, July 2011.

[15] A. M. Fayrushin, R. R. Chernyatyeva, and D. N. Yakovleva, "The Effects of Vibration Treatment in the Process of Welding on the Structure of Metal of Seam Weld," IOP Conference Series: Earth and Environmental Science, vol. 459 , 062110, 2020.

[16] H. Gao, S. Wu, Q. Wu, B. Li, Z. Gao, Y. Zhang, et al., "Experimental and Simulation Investigation on Thermal-Vibratory Stress Relief Process for 7075 Aluminum Alloy," Materials and Design, vol. 195, 108954, October 2020.

[17] D. X. Fang, F. H. Sun, Z. K. Gong, A. X. Jia, and Y. A. Qu, "Improving Fatigue Life of Welded Components by Vibratory Stress Relief Technique,” International Journal Experiment Mechanical, vol. 6, pp. 89-95, 1991.

[18] A. Munsi, A. J. Waddell, and C. Walker, "The Influence of Vibratory Treatment on the Fatigue Life of Welds: A Comparison with Thermal Stress Relief," Strain, vol. 37, no. 4, pp. 141-149, 2001.

[19] D. Djuric, R. Vallant, K. Kerschbaumer, and N. Enzinger, "Vibration Stress Relief Treatment of Welded High-Strength Martensitic Steel," Welding in the World, vol. 55, no. 1, pp. 86-93, 2011.

[20] H. J. Gao, Y. D. Zhang, Q. Wu, and J. Song, "Experimental Investigation on the Fatigue Life of Ti-6Al-4V Treated by Vibratory Stress Relief," Metals, vol. 7, no. 5, 158, May 2017.

[21] J. Song and Y. Zhang, "Effect of Vibratory Stress Relief on Fatigue Life of Aluminum Alloy 7075-T651," Advances in Mechanical Engineering, vol. 8, no. 6, pp. 1-9, 2016.

[22] H. Gao, Y. Zhang, Q. Wua, J. Song, and K. Wen, "Fatigue Life of 7075-T651 Aluminum Alloy Treated with Vibratory Stress Relief," International Journal of Fatigue, vol. 108, pp. 62-67, March 2018.

[23] Standard Test Method for Determining Residual Stresses by the Hole-Drilling Strain-Gage Method, ASTM E837-13a, 2013.

[24] M. Kuroda, A. Sakida, N. Oguma, M. Nakagawa, T. Matsumura, and T. Sakai, "Historical Review on Origin and Application to Metal Fatigue of Probit and Staircase Method and Their Future Prospects," Journal of the Society of Materials Science, vol. 70, no. 3, pp. 221-228, March 2021.

[25] C. Müller, M. Wächter, R. Masendorf, and A. Esderts, "Accuracy of Fatigue Limits Estimated by the Staircase Method Using Different Evaluation Techniques,” International Journal of Fatigue, vol. 100, pp. 296-307, July 2017.

[26] H. Xue, R. R. Li, L. X. Wu, W. J. Peng, and J. Q. Huang, “The Fatigue Performance Evaluation of Pressure Vessel Steel Using Modified Staircase Method,” Advanced Materials Research, vol. 989, pp. 879-882, 2014.

[27] I. M. W. Ekaputra, R. T. Dewa, G. D. Haryadi, and S. J. Kim, "Fatigue Strength Analysis of S34MnV Steel by Accelerated Staircase Test," Open Engineering, vol. 10, no. 1, pp. 394-400, 2020.

[28] International Council on Combustion Engines Working Group 4 (CIMAC WG4), "IACS UR M53, Appendix IV, Guidance for Evaluation of Fatigue Tests," Report, October 16, 2009.

[29] Strength Calculation and Testing: Methods of Fatigue Strength Behavior Calculation, GOST 25.504-82, 1982. (In Russian)

Copyright $($ by the authors. Licensee TAETI, Taiwan. This article is an open access article distributed under the terms and conditions of the Creative Commons Attribution (CC BY-NC) license (https://creativecommons.org/licenses/by-nc/4.0/). 